\title{
Retraction Note to: Preparation of Multilayers Zinc Hydroxystannate Microcapsules and its Application in Flame-Retardant PVC Composites
}

\author{
Bin Zhang ${ }^{1} \cdot$ Yujie Jiang $^{1} \cdot$ Jian $\operatorname{Han}^{1}$
}

Published online: 18 June 2019

(C) Springer Nature B.V. 2019

Retraction Note to: Silicon (2018) 10:2845-2854

https://doi.org/10.1007/s12633-018-9824-1

The authors have retracted this article (1) because the data are unreliable. After publication, the authors found that the preparation of the $\mathrm{SiO} 2 / \mathrm{ZHS}$ and the $\mathrm{MF} / \mathrm{SiO} 2 / \mathrm{ZHS}$ microcapsules is not reproducible and therefore the mechanical properties and the flame retardancy properties described are incorrect.

*All authors agree to this retraction.

Publisher's Note Springer Nature remains neutral with regard to jurisdictional claims in published maps and institutional affiliations.

The online version of the original article can be found at https://doi.org/ 10.1007/s12633-018-9824-1

Jian Han

hanjian8@zstu.edu.cn

Zhejiang Provincial Key Laboratory of Industrial Textile Materials \& Manufacturing Technology, College of Materials and Textiles, Zhejiang Sci-Tech University, Hangzhou 310018, People's Republic of China 